\title{
Classification of behavioral signs of the mares for prediction of the pre-foaling period
}

\author{
Youngwook Jung ${ }^{1}$, Heejun Jung ${ }^{1}$, Yongseok Jang ${ }^{2}$, Duhak Yoon ${ }^{1, *}$ and Minjung Yoon ${ }^{1,3, *}$ \\ ${ }^{1}$ Department of Animal Science and Biotechnology, Kyungpook National University, Sangju 37224, Korea \\ ${ }^{2}$ Yujung Breeding Center, Sangju 37275, Korea \\ ${ }^{3}$ Department of Horse, Companion and Wild Animal Science, Kyungpook National University, Sangju 37224, Korea
}

Received May 27, 2021

Revised June 15, 2021

Accepted June 16, 2021

*Correspondence

Minjung Yoon

E-mail: mjyoonemail@gmail.com

ORCID

https://orcid.org/0000-0001-9112-1796

Duhak Yoon

E-mail: dhyoon@knu.ac.kr

ORCID

https://orcid.org/0000-0002-3983-9757

\begin{abstract}
In horse management, the alarm system with sensors in the foaling period enables the breeder can appropriately prepare the time of the parturition. It is important to prevent losses by unpredictable parturition because there are several high risks such as dystocia and the death of foals and mares during foaling. However, unlike analysis in the alarm system that detects specific motions has been widely performed, analysis of classification following specific behavior patterns or number needs to be more organized. Thus, the objective of this study is to classify signs of the specific behaviors of the mares for the prediction of pre-foaling behaviors. Five Thoroughbred mares (9-20 yrs) were randomly selected for observation of the prefoaling behaviors. The behaviors were monitored for $90 \mathrm{~min}$ that was divided into three different periods as 1) from -90 to $-60 \mathrm{~min}, 2)$ from -60 to $-30 \mathrm{~min}, 3)$ from $-30 \mathrm{~min}$ to the time for the discharge of the amniotic fluid, respectively. The behaviors were divided into two different categories as state and frequent behaviors and each specific behavioral pattern for classification was individually described. In the state behaviors, the number of mares in the standing of the foaling group $\left(3.17 \pm 0.18^{b}\right)$ at period 3 was significantly higher than the control group $\left(1.67 \pm 0.46^{\mathrm{a}}\right)$. In contrast, the number of the mares in the eating of the foaling group $\left(1.17 \pm 0.34^{\mathrm{b}}\right)$ at period 3 was significantly lower than the control group $\left(3.33 \pm 0.46^{\mathrm{a}}\right)$. In the frequent behaviors, the weaving of the foaling group was significantly higher than the control group, and looking at the belly of the foaling group was significantly lower than the control group. In period 2 , defecation, weaving, and lowering the head of the foaling group were significantly higher than the control group, respectively. In period 3, sitting down and standing up, pawing, weaving, and lowering the head in the foaling group were also significantly higher than the control group. In conclusion, the behavior is significantly different in foaling periods, and the prediction of foaling may be feasible by the detection of the pre-foaling behaviors in the mares.
\end{abstract}

Keywords: behaviors, horse, mare, sensor

\section{INTRODUCTION}

Assistants should be accompanied to mares during foaling for several reasons. A high rate of dystocia with a high risk of death of foals an mares was recorded during foaling (Morley and Townsend, 1997). In recent days, several studies have tried to understand mare's reproductive physiology with respect to their reproductive hor- 
mone, seasonal effect to reproductive organ, device for controlling seasonal effect and biotechnology for embryo transfer (Park et al., 2017; Yu et al., 2017; Lee et al., 2020; Seong et al., 2020). Especially, the foaling is considered as one of main topics among several fields of reproductive physiology of mares. Typically, foal mortality significantly increases when delivery of foals is not completed within 40 min after the initiation of the $2^{\text {nd }}$ stage of foaling (McCue and Ferris, 2012). Dystocia and delayed foaling of mares can be easily treated if assistance is available. The health status of foals should be checked right after foaling to treat them immediately if foals have abnormal symptoms (Acworth, 2003; Carr, 2014). Immediately after foaling, the placenta should be tangled up by breeders. Mares that step on the placenta may result in a piece of the placenta becoming torn and remaining in the uterus, which causes serious toxicity (Canisso et al., 2013; Hussein et al., 2015; Warnakulasooriya et al., 2018; Schürmann et al., 2019). Furthermore, mares experiencing a retained placenta should get treated in a short period (Vandeplassche et al., 1971; Burden et al., 2019). In the case of Thoroughbreds, $86 \%$ of foaling occurs from 19:00 to 7:00, so breeders seldom fail to be accompanied by mares during foaling (Rossdale and Short, 1967). Thus, the development of a reliable foaling alarm system can be a useful tool for horse breeders.

Currently, several foaling alarm systems have been invented and are used in the horse breeding industry. However, the pitfalls of these devices have yet to be overcome. Foalert ${ }^{\mathrm{TM}}$ is the first device invented as a foaling alarm system. This device is designed to operate when two devices attached to each side of the vulva are separated at the time of amniotic fluid rupture. Foalert ${ }^{\mathrm{TM}}$ transmits the signal at the end of the $1^{\text {st }}$ trimester to alert that immediate assistance is needed. Thus, assistants might not arrive at the right time. Another pitfall of this device is that it requires a surgical procedure to attach the device to the vulva of mares. The Smart Foal ${ }^{\mathrm{TM}}$ device is another popular foaling alarm system. The main sensor of the Smart Foal $^{\mathrm{TM}}$ device detects horse rolling behavior, which usually takes place right at the end of $1^{\text {st }}$ trimester. Rolling is not only a pre-foaling behavior, but it also can be seen when horses are itching or have colic, and horses usually roll when new bedding is provided in the stall. Therefore, this device may cause false alarms. In another study, an accelerometer attached to the base of the tail was used to detect pre-foaling signs of Thoroughbreds. Near the time of foaling, the duration of tail movement decreased while the frequency of tail movement increased (AuclairRonzaud et al., 2020).

The fine foaling alarm system should be operated at the right time with high accuracy. The system should notify of the event at the beginning of the $1^{\text {st }}$ trimester so that assistants can be at the site before foaling begins. Furthermore, the system should be easily operated by breeders. Therefore, the development of a new foaling alarm system that is easy to use and accurately operates at the right time is in high demand.

The best time to install an advanced alarm device is the beginning of $1^{\text {st }}$ trimester. In addition, the breeders should continuously be notified about the ongoing process of foaling. Thus, it is critical to investigate various prefoaling behaviors throughout the whole foaling process. Mares show various types of pre-foaling behaviors. Shaw et al. (1988) investigated pre-foaling and foaling behaviors, such as walking, lying (sternal and lateral), eating, and standing behavior. However, the result of that study reported changes in those five pre-foaling behaviors only, which is inadequate information for establishing a module for a foaling alarm system. Thus, further study to observe additional specific pre-foaling behaviors, such as sitting down and standing up, defecating, urinating, pawing, weaving, lowering the head, and looking at the belly (flank watching) should be conducted.

The foaling alarm system should be equipped with several sensors to quantify the occurrence of several kinds of behaviors. Thus, detailed pre-foaling behaviors should be observed so that optimal sensors can be selected for foaling alarm devices. Therefore, the objective of this study is to analyze specific pre-foaling behaviors of Thoroughbred horses.

\section{MATERIALS AND METHODS}

\section{Animals}

All procedures for this study were approved by the Animal Experimentation Ethics Committee of Kyungpook National University (approval number: 2020-0140). The present study was performed at a Thoroughbred breeding farm located in Sangju city, Republic of Korea (geographical coordinates: $36^{\circ} 19^{\prime} 52.7412^{\prime \prime} \mathrm{N}, 127^{\circ} 56^{\prime} 05.5392$ ” E). Five Thoroughbred mares (9-20 yrs) were randomly 
selected for observation of the foaling behaviors in a sawdust bedded stall. Horses were grazed during the daytime (9:00 to 18:00) and stayed in the $3.5 \times 3.5 \mathrm{~m}$ stall at night (18:00 to 09:00). In the stall, horses were fed with $0.8 \%$ body weight (dry matter) of concentrate, twice a day. Timothy hay and water were provided ad libitum. The mean atmosphere temperature during the observation period was approximately $4.2^{\circ} \mathrm{C}$ in the region.

\section{Behavioral data}

To analyze the pre-foaling behaviors, a video recorder (DS-7204HQHI-K1, HIKVISION, China) was used to record the behavior patterns during foaling. Discharge of amniotic fluid was considered as a sign the onset of foaling and the behaviors for pre-foaling were divided into 3

Table 1. Description of categorized periods

\begin{tabular}{cl}
\hline Period category & \multicolumn{1}{c}{ Description } \\
\hline Period 1 & From -90 min to -60 min \\
Period 2 & From -60 min to -30 min \\
Period 3 & $\begin{array}{c}\text { From }-30 \text { min to the time for the discharge of the } \\
\text { amniotic fluid }\end{array}$ \\
\hline
\end{tabular}

different period categories as follows: 1) from $-90 \mathrm{~min}$ to $-60 \mathrm{~min}, 2)$ from $-60 \mathrm{~min}$ to $-30 \mathrm{~min}$, and 3) from $30 \mathrm{~min}$ to the time for the discharge of the amniotic fluid, respectively (Table 1). Ethogram was described to organize the features of specific behavior patterns of the mare following to pre-foaling period (Table 2). In the number of behavior patterns, the data between 2 days before foaling (day -2) and foaling (foaling day, not after foaling) was analyzed to compare the differences and the data based on 2 days before beginning discharge of the amniotic fluid was used as a control group (Table 3 and 4).

\section{Statistical analysis}

Analysis of variance (ANOVA) was performed using the general linear models procedure of SAS software (SAS Institute, NC, USA). Significant differences in the behavior data were detected using the least squares method with Bonferroni correction for multiple comparisons. The mean value and standard error of the mean (SEM) were calculated after recording the specific number of horse behavior. $p$-values $<0.05$ were considered statistically significant.

Table 2. Ethogram for pre-foaling behaviors in the mares

\begin{tabular}{cll}
\hline Behavioral category & \multicolumn{1}{c}{ Behavior } & \multicolumn{1}{c}{ Description } \\
\hline State behavior & Lateral recumbency & Horses lying sideways with the flank attached to the ground \\
& Sternal recumbency & Horses lying with the lower abdomen on the ground and head in the air \\
& Standing & Horses four legs on the ground, except for eating \\
& Walking & Horses moving more than a step \\
& Eating & Horses drinking water and eating hay, concentrate feed, or bedding material without moving \\
Frequent behavior & Sitting down and standing up & Horses sitting and standing up \\
& Defecation & Horses discharging feces \\
& Urination & Horses discharging urine \\
& Pawing & Horses scratching the floor with their front legs \\
& Weaving & Horses shaking their head from side to side \\
& Lowering the head & Horses lowering their head without eating \\
& Looking at the belly & Horses turning their head and looking at the abdomen \\
\hline
\end{tabular}

Table 3. The number of mares in pre-foaling state behavior observed every $5 \mathrm{~min}$ in each period

\begin{tabular}{|c|c|c|c|c|c|c|}
\hline & \multicolumn{2}{|c|}{ Period 1 ( -90 to -60 mins) } & \multicolumn{2}{|c|}{ Period 2 ( -60 to -30 mins) } & \multicolumn{2}{|c|}{ Period 3 ( -30 to -0 mins) } \\
\hline & Day -2 & Foaling & Day -2 & Foaling & Day -2 & Foaling \\
\hline Lateral recumbency & 0 & 0 & 0 & 0 & 0 & $0.17 \pm 0.18$ \\
\hline Sternal recumbency & 0 & 0 & 0 & 0 & 0 & $0.17 \pm 0.18$ \\
\hline Standing & $2.50 \pm 0.47$ & $1.67 \pm 0.23$ & $1.83 \pm 0.34$ & $2.67 \pm 0.46$ & $1.67 \pm 0.46^{\mathrm{a}}$ & $3.17 \pm 0.18^{b}$ \\
\hline Walking & 0 & $0.33 \pm 0.23$ & $0.17 \pm 0.18$ & $0.33 \pm 0.23$ & 0 & $0.33 \pm 0.23$ \\
\hline Eating & $2.17 \pm 0.59$ & $2.50 \pm 0.47$ & $3.00 \pm 0.28$ & $2.00 \pm 0.56$ & $3.33 \pm 0.46^{\mathrm{a}}$ & $1.17 \pm 0.34^{b}$ \\
\hline
\end{tabular}

Different superscripts indicate a significant difference $(p<0.05)$. 
Table 4. The number of mares in pre-foaling behaviors observed throughout the whole period

\begin{tabular}{|c|c|c|c|c|c|c|}
\hline & \multicolumn{2}{|c|}{ Period 1 ( -90 to -60 mins) } & \multicolumn{2}{|c|}{ Period 2 ( -60 to -30 mins) } & \multicolumn{2}{|c|}{ Period 3 ( -30 to -0 mins) } \\
\hline & Day -2 & Foaling & Day -2 & Foaling & Day -2 & Foaling \\
\hline Sitting down and standing up & 0 & 0 & 0 & 0 & $0^{a}$ & $1.00 \pm 0.56^{b}$ \\
\hline Defecation & $0.17 \pm 0.18$ & $0.17 \pm 0.18$ & $0^{a}$ & $0.50 \pm 0.24^{b}$ & $0.17 \pm 0.18$ & $0.33 \pm 0.23$ \\
\hline Urination & $0.33 \pm 0.36$ & $0.33 \pm 0.23$ & $0.17 \pm 0.18$ & 0 & 0 & $0.17 \pm 0.18$ \\
\hline Pawing & 0 & 0 & 0 & $0.33 \pm 0.23$ & $0^{\mathrm{a}}$ & $0.83 \pm 0.34^{b}$ \\
\hline Weaving & $0.33 \pm 0.23^{\mathrm{a}}$ & $1.00^{b}$ & $0^{a}$ & $1.17 \pm 0.18^{b}$ & $0.17 \pm 0.18^{a}$ & $0.67 \pm 0.23^{b}$ \\
\hline Lowering the head & $1.17 \pm 0.44$ & $1.67 \pm 0.61$ & $1.67 \pm 0.36^{a}$ & $3.67 \pm 0.23^{b}$ & $1.50 \pm 0.62^{\mathrm{a}}$ & $4.67 \pm 0.23^{b}$ \\
\hline Looking at the belly & $2.83 \pm 0.44^{a}$ & $1.50 \pm 0.37^{b}$ & $2.83 \pm 0.66$ & $3.33 \pm 0.23$ & $2.33 \pm 0.54$ & $3.50 \pm 0.47$ \\
\hline
\end{tabular}

Different superscripts indicate significant difference $(p<0.05)$.

\section{RESULTS}

\section{Pre-foaling state behaviors}

The state behaviors of the mares were monitored and analyzed every 5 min based on a description of the categorized period of the foaling (Table 1) and each specific state behavior (Table 3 ), respectively. In period 3 (-30 to $-0 \mathrm{~min}$ ), the only 2 behaviors (standing and eating) of the described various behaviors were significantly $(p<0.05)$ different between day -2 and foaling groups, respectively. In standing behavior, the number of mares in standing in the foaling group $(3.17 \pm 0.18)$ at period 3 was significantly $(p<0.05)$ higher than the day -2 group $(1.67 \pm$ $0.46)$. In contrast, the number of mares in eating of the foaling group $(1.17 \pm 0.34)$ at period 3 was significantly $(p<0.05)$ lower than the day -2 group $(3.33 \pm 0.46)$. The other behaviors such as lateral and sternal recumbency, and walking were not significantly different in all periods.

\section{Pre-foaling frequent behaviors}

The frequent behaviors of the mares were monitored between intervals of $5 \mathrm{~min}$ for the purposed period time (Table 4). The 7 different behavior patterns were categorized as sitting down and standing up, defecation, urination, pawing, weaving, lowering the head, and looking at the belly. In period 1, weaving of foaling group was significantly $(p<0.05)$ higher than day -2 group and looking at the belly of day -2 group was significantly $(p<0.05)$ higher than foaling group, respectively. In period 2 , defecation of foaling group $(0.50 \pm 0.24)$ was significantly $(p<0.05)$ higher than day -2 group (0). Additionally, weaving (1.17 \pm $0.18)$ and lowering the head $(3.67 \pm 0.23)$ in the foaling group were also significantly $(p<0.05)$ higher than the day -2 group ( 0 and $1.67 \pm 0.36$ ), respectively. In period 3 , sit- ting down and standing up, pawing, weaving, and lowering the head in the foaling group were significantly $(p<0.05)$ higher than the day -2 group $(p<0.05)$.

\section{DISCUSSION}

In the present study, the pregnant mares were monitored to classify the behavioral indications that can predict the pre-foaling period using a video information transmitter and the categorized behavior patterns were compared with normal behaviors (control, day -2). The number of sitting down and standing up behaviors was significantly higher in period 3 compared with that of a normal day, which indicates that this behavior is a prefoaling sign. Sitting down and standing up behaviors are often exhibited by horses who are suffering from diseases such as colic (Pritchett et al., 2003). An altitude sensor such as BMP280 that can perceive changes in the height of the sensor target may be used to detect the behavior of sitting down and standing up. An accelerometer sensor such as MPU6050, which senses the three-axis movement of an object, can also be used to detect sitting down and standing up behavior. Because horses seldom show sitting down and standing up behavior, additional typical prefoaling behaviors should be added to the new system.

A higher number of mares in pawing behavior was observed in period 3 compared with that of a normal day. During pawing, the mares drag one of their front legs on the ground. Horses frequently show this type of behavior when they feel frustration, pain, or/and stress (Houpt and McDonnell, 1993; Minero et al., 2006). According to a previous study, the average heart rate (HR) of horses showing pawing behavior increases (Minero et al., 2006). Also, electromyographic (EMG) data was strictly corre- 
lated with HR in another study (Giovagnoli et al., 2002). Thus, this pre-foaling sign can be detected by monitoring changes in the mares using HR and EMG sensors.

The number of mares in lowering the head behavior was significantly higher from periods $2-3$ in comparison with that of a normal day, which indicates that this behavior may be regarded as pre-foaling behavior. This behavior is often associated with unrelenting pain (Ashley et al., 2005). To exactly detect this type of behavior, altitude and accelerometer sensors should be attached to the halter. Lowering the head behavior was also often observed during the post-foaling periods. During this time, mares lower their head to smell and lick their infants.

In the present study, a higher number of mares in lateral and sternal recumbency was observed after the amniotic sac ruptured compared with that of a normal day. This behavior can be easily detected with altitude and accelerometer sensors. An emergent foaling assistant should be applied when the foal does not come out within $30 \mathrm{~min}$ after amniotic sac rupture. Thus, the foaling alarm system should be developed to trigger a signal before amniotic sac discharge, which means that sensors that only detect the data module for lateral and sternal recumbency are not suitable. The foaling alarm system should be operated to detect other pre-foaling behaviors as well.

The placement of sensors is an important factor in detecting a specific pre-foaling behavior. In the present study, the mares in weaving behavior, which is categorized as abnormal locomotion, were higher during periods 1 to 3 in comparison with that of a normal day (Ashley et al., 2005). This result indicates that weaving behavior is one of the specific pre-foaling behaviors that can be detected as early as $90 \mathrm{~min}$ before amniotic sac discharge. Therefore, weaving behavior should be monitored to detect prefoaling signs. The weaving behavior can be monitored by halter-attached altitude and accelerometer sensors.

The number of mares in scanned standing behavior significantly increased in period 3. The mares in eating behavior have also reduced from period 3 in comparison with that of a normal day. Based on the observation results, standing behavior was affected by a reduction of eating behavior in period 3. The behaviors such as walking, defecation, and urination were not considered to be specific signs of pre-foaling because these behaviors are considered to be routinely exhibited horse behaviors even when they are stable. Looking at the belly (flank watching) behavior is known as a sign of pain and is regarded as a major pre-foaling sign (Sanchez and Robertson, 2014). However, in the present study, the number of mares in looking at the belly compared with that of a normal day was not significant.

There are several types of foaling alarm systems that detect various pre-foaling signs. Haluska and Wilkins (1989) and Cross et al. (1992) reported that rectal temperature decreased before foaling (especially $3-4$ hours before) and increased after foaling until 24-48 hours. Recently, Auclair-Ronzaud et al. (2020) compared the temperature of mares during the pregnancy period and foaling days by using a neckline implanted microchip. Similar to the rectal temperature measurement, body temperature decreased before foaling, and the correlation between the temperature and behavior of pre-foaling was analyzed. Nagel et al. (2012) revealed that the HR was comparatively constant for 15 days before foaling but significantly decreased during the foaling period. According to previous studies, changes in body temperature and HR can be also used as a pre-foaling sign. Based on the result of the previous study, a pre-foaling detection device should be equipped with a thermometer and HR or EMG sensors.

\section{CONCLUSION}

In conclusion, an optimal foaling alarm system should be equipped with altitude and accelerometer sensors as well as HR and EMG sensors. In addition, the system should be equipped with a thermometer sensor to detect the changes in the temperature of pre-foaling mares.

\section{CONFLICTS OF INTEREST}

No potential conflict of interest relevant to this article was reported.

\section{ACKNOWLEDGEMENTS}

The authors would like to thank Junyoung Kim, Yeonju Choi, Seongmin Kim, and Yubin Song for their assistance with data collection. The authors also thank the Korean Racing Authority for their assistance. This work was supported by the Korea Institute of Planning and Evaluation for Technology in Food, Agriculture, and Forestry (320017021HD020). 


\section{AUTHOR CONTRIBUTIONS}

\author{
Conceptualization: Minjung Yoon \\ Data curation: Minjung Yoon \\ Formal analysis: Minjung Yoon \\ Funding acquisition: Minjung Yoon \\ Investigation: Minjung Yoon \\ Methodology: Minjung Yoon \\ Project administration: Minjung Yoon \\ Resources: Yongseok Jang, Minjung Yoon \\ Software: Minjung Yoon \\ Supervision: Duhak Yoon, Minjung Yoon \\ Validation: Heejun Jung, Duhak Yoon, Minjung Yoon \\ Visualization: Youngwook Jung \\ Writing - original draft: Youngwook Jung \\ Writing - review \& editing: Heejun Jung, Duhak Yoon, \\ Minjung Yoon
}

\section{AUTHOR'S POSITION AND ORCID NO.}

\author{
Y Jung, MS Student, \\ https://orcid.org/0000-0002-7829-0349 \\ H Jung, Professor, \\ https://orcid.org/0000-0001-9608-1412 \\ Y Jang, Project Fellow, \\ https://orcid.org/0000-0002-2043-4362 \\ D Yoon, Professor, \\ https://orcid.org/0000-0002-3983-9757 \\ M Yoon, Professor, \\ https://orcid.org/0000-0001-9112-1796
}

\section{REFERENCES}

Acworth NRJ. 2003. The healthy neonatal foal: routine examinations and preventative medicine. Equine Vet. Educ. 15:207-211.

Ashley FH, Waterman-Pearson AE, Whay HR. 2005. Behavioural assessment of pain in horses and donkeys: application to clinical practice and future studies. Equine Vet. J. 37:565-575.

Auclair-Ronzaud J, Jousset T, Dubois C, Wimel L, Jaffrézic F, Chavatte-Palmer P. 2020. No-contact microchip measurements of body temperature and behavioural changes prior to foaling. Theriogenology 157:399-406.

Burden CA, Meijer M, Pozor MA, Macpherson ML. 2019. Fetal membrane removal in the mare: proactive versus reactive approaches. Vet. Clin. North Am. Equine Pract. 35:289-298.

Canisso IF, Rodriguez JS, Sanz MG, Coutinho da Silva MA. 2013. A clinical approach to the diagnosis and treatment of retained fetal membranes with an emphasis placed on the critically ill mare. J. Equine Vet. Sci. 33:570-579.

Carr EA. 2014. Field triage of the neonatal foal. Vet. Clin. North Am. Equine Pract. 30:283-300, vii.

Cross DT, Threlfall WR, Kline RC. 1992. Body temperature fluctuations in the periparturient horse mare. Theriogenology 37:1041-1048.

Giovagnoli G, Trabalza Marinucci M, Bolla A, Borghese A. 2002. Transport stress in horses: an electromyographic study on balance preservation. Livest. Prod. Sci. 73:247-254.

Haluska GJ and Wilkins K. 1989. Predictive utility of pre-partum temperature changes in the mare. Equine Vet. J. 21:116-118.

Houpt KA and McDonnell SM. 1993. Equine stereotypies. Compend. Contin. Educ. Pract. Vet. 15:1265-1271.

Hussein HA, Loose M, Wehrend A. 2015. [Incidence of puerperal diseases during the first 10 days after foaling in the mare]. Tierarztl. Prax. Ausg. G Grosstiere Nutztiere 43:150153. German.

Lee G, Jung H, Yoon M. 2020. The effect of Equilume light masks on the timing of seasonal ovulation of Thoroughbred mares in South Korea. J. Anim. Reprod. Biotechnol. 35:171176.

McCue PM and Ferris RA. 2012. Parturition, dystocia and foal survival: a retrospective study of 1047 births. Equine Vet. J. Suppl. (41):22-25.

Minero M, Zucca D, Canali E. 2006. A note on reaction to novel stimulus and restraint by therapeutic riding horses. Appl. Anim. Behav. Sci. 97:335-342.

Morley PS and Townsend HG. 1997. A survey of reproductive performance in Thoroughbred mares and morbidity, mortality and athletic potential of their foals. Equine Vet. J. 29:290-297.

Nagel C, Erber R, Bergmaier C, Wulf M, Aurich J, Möstl E, Aurich C. 2012. Cortisol and progestin release, heart rate and heart rate variability in the pregnant and postpartum mare, fetus and newborn foal. Theriogenology 78:759-767.

Park YS, Yang JH, Cho YJ, Oh DY, Cho GJ. 2017. Embryo collection, transfer and pregnancy of riding horses: first successful case in Korea. J. Emb. Trans. 32:59-64.

Pritchett LC, Ulibarri C, Roberts MC, Schneider RK, Sellon DC. 2003. Identification of potential physiological and behavioral indicators of postoperative pain in horses after exploratory celiotomy for colic. Appl. Anim. Behav. Sci. 80:31-43.

Rossdale PD and Short RV. 1967. The time of foaling of thoroughbred mares. J. Reprod. Fertil. 13:341-343.

Sanchez LC and Robertson SA. 2014. Pain control in horses: what do we really know? Equine Vet. J. 46:517-523.

Schürmann C, Loose M, Failing K, Wehrend A. 2019. [Retained placenta in mares - an analysis of 121 cases]. Tierarztl. Prax. Ausg. G Grosstiere Nutztiere 47:373-379. German.

Seong HK, Choi SH, Byambaragchaa M, Min KS. 2020. Signal transduction of C-terminal phosphorylation sites for equine follicle stimulating hormone receptor (eFSHR). J. Anim. Reprod. Biotechnol. 35:155-162.

Shaw EB, Houpt KA, Holmes DF. 1988. Body temperature and 
behaviour of mares during the last two weeks of pregnancy. Equine Vet. J. 20:199-202.

Vandeplassche M, Spincemaille J, Bouters R. 1971. Aetiology, pathogenesis and treatment of retained placenta in the mare. Equine Vet. J. 3:144-147.

Warnakulasooriya DN, Marth CD, McLeod JA, Hanlon DW,
Krekeler N. 2018. Treatment of retained fetal membranes in the mare-a practitioner survey. Front. Vet. Sci. 5:128.

Yu YJ, Park SH, Shin SM, Yang BC, Seong PN, Woo JH, Kim NY, Son JK. 2017. Effect of ovarian changes according to four season for reproduction of Jeju crossbred horses. J. Emb. Trans. 32:177-182. 